\title{
Bibliometric Analysis of Phosphogypsum Research from 1990 to 2020 Based on Literatures and Patents
}

\author{
Yunmeng Cao \\ Nankai University \\ Yue Cui \\ Nankai University \\ Xiaokun Yu \\ Nankai University \\ Tong Li \\ Nankai University \\ I-shin Chang \\ Nankai University \\ Jing WU ( $\nabla$ wujing@nankai.edu.cn ) \\ Nankai University
}

\section{Research Article}

Keywords: Phosphogypsum, Bibliometric, Knowledge map, Citespace, Technology life cycle, S-curve

Posted Date: April 19th, 2021

DOl: https://doi.org/10.21203/rs.3.rs-376644/v1

License: (1) This work is licensed under a Creative Commons Attribution 4.0 International License. Read Full License

Version of Record: A version of this preprint was published at Environmental Science and Pollution Research on July 8th, 2021. See the published version at https://doi.org/10.1007/s11356-021-15237-y. 


\section{Abstract}

The demand together with the urgency of phosphogypsum (PG) treatment, will pose big challenges for many countries. This research aims to explore the research progress of PG, including basic status, cooperation situation, research fields and development trends, based on Web of Science database through bibliometric analysis of publications (articles and patents) from 1990 to 2020. The results show that the academic research of PG originated earlier, but the number of patents grew faster. China has an absolute advantage in the numbers and plays a significant role in international cooperation. The knowledge structure of PG is mainly concentrated in the fields of natural radioactivity, cement paste backfilling, soil, crystal morphology, and synthetic gas. Academic hotspots focus on the microstructure of chemical processes and various environmental impacts, and the patents hot technologies is the production of refractory materials, ceramics, surface materials, cement mortar and composite materials. The academic frontiers of PG will be the methods of recovering rare earth elements from PG, the conditions of ion solidification/stabilization in PG, the impact of reaction conditions on product quality, and the reaction mechanism at the micro-level. The frontiers of patents will focus on the improvement of manufacturing equipment, new wall materials and chemical modified polymer materials. In terms of the number of articles and patents in the future, architectural research has the maximum space for improvement. This paper conducts an in-depth analysis of PG and provides information on the technological development prospects and opportunities, which is helpful for researchers engaged in PG management.

\section{Introduction}

Phosphorus chemical industry refers to a chemical sub-industry that uses phosphate ore and sulfur as the raw materials to produce phosphorus. The products of the phosphorus chemical industry have been widely used in various industries, national defense, cuttingedge science, and people's lives (Zhang and Zhang, 2018). Phosphogypsum ( $\mathrm{PG}$, mainly $\mathrm{CaSO}_{4} \cdot 2 \mathrm{H}_{2} \mathrm{O}$ ) is the by-product of wet process phosphoric acid production (Beretka et al., 1993). According to estimates, the production of 1 ton of phosphoric acid (calculated as $\mathrm{P}_{2} \mathrm{O}_{5}$ ) will approximately produce 5 tons of PG, which are mainly discharged, stored or reused (Chen et al., 2018). As the expansion of the phosphorus chemical industry and the requirements of environmental protection, currently, piling up on the ground is the main treatment of PG, which not only occupies lots of lands, but also causes severe environmental pollution (Mohammed et al., 2018; Moreira et al., 2018). Nowadays, about 20-30 billion tons of PG are produced annually worldwide to pose tremendous pressure on environmental protection and create a huge challenge to its recycling (Pérez-López et al., 2016).

Since PG has the characteristics of large output, concentrated distribution, and complex composition, the current disposal method is the coexistence of storage and utilization (Zhou et al.), as shown in Fig. 1. After pretreatment, PG can be directly used as final products such as mine filling materials, roadbed materials, and soil conditioners (Gu et al., 2020). In addition, PG can also produce raw materials such as sulfuric acid co-production cement, construction gypsum powder, cement retarder, and other building materials indirectly (Chen et al., 2018). At present, many scholars have done a lot of research on the environmental impacts and treatment technologies of PG, such as the radiological and elemental hazards (Attallah et al., 2019; Qamouche et al., 2020), the behaviour of heavy metals (Guerrero et al., 2021; Vasconez-Maza et al., 2021), optimum design of PG storage yard (Millan-Becerro et al., 2020), and the pretreatment to remove impurities (Zhang and Zhang, 2018). Most studies, however, are expert-dependent. To a certain extent, this individual and subjectivity preference leads to a lack of systematic and quantitative summary in this field, making it difficult to understand the overall structure of the intellectual landscape of PG from a macro perspective.

Bibliometric is an effective tool for quantitative analysis of academic literature through mathematical statistics techniques. It has been widely used in various disciplines to explore the distribution of articles in a particular field of countries, institutions and topics (Peng et al., 2018). More importantly, the combination of literature and patent results is conducive to identifying the relationship between fundamental research and applied research, exploring the direction and content of technological development, so as to better understand the direction of future theoretical and technological innovation (Zhang et al., 2020). However, to the best of our knowledge, no attempt has been made to analysis the field of PG by bibliometric.

In order to fill the gap in previous research, this study employed the bibliometric analysis to quantitatively and qualitatively discuss the publications in the field of PG from 1990 to 2020, based on articles and patents. More specifically, we explored (1) the current status of PG domain, such as the distribution of annual output, disciplines, journals, countries and institutions; (2) the performance of countries, institutions, and individuals in the cooperation network; (3) the foundation, hot areas and frontiers of PG study by the co-citation, cooccurrence and burst value of articles and patents respectively; (4) the technology life cycle curve and future development trend of each sub-field. This empirical research supplements the traditional narrative-based literature review quantitatively, and provides a comprehensive and scientific guidance for future studies. 


\section{Data Acquisition And Research Methods \\ 2.1 Data acquisition}

The data in this paper were all downloaded from Web of Science. Scientific literatures were retrieved using Science Citation Index Expanded (SCIE) and Social Science Citation Index (SSCI), and the patent data came from Derwent Innovation Index (DII).

SCIE and SSCl are commonly used databases in bibliometric analysis (Liu and Liao, 2017). They cover more scientific and authoritative publications than other databases, and provide information such as citations, keywords and references for subsequent in-depth bibliometric. DII, the integration of Derwent World Patents Index ${ }^{\circledR}$ (DWPI) and Derwent Patents Citation Index $($ DPCl) is a web-based patent information database published by Thomson Derwent and Thomson ISI, jointly (Lv et al., 2011), where the adequacy, reliability, and sufficiency of the data can be fully guaranteed. As one of the major features of the DII database, Derwent Manual Code (DMC) is the proprietary codes of patented technology classifications, used as an identification of patent (Wang et al., 2011).

We took "Title = (phosphogypsum)" as retrieval stratage and the time span was defined as "1990-2020" (Retrieval date: October 20, 2020). In order to improve the quality of retrieval results and avoid the interference of subjective reviews, the literature type was limited to "article". In total, 748 articles and 2617 patents met the selection criteria. Afterward, through manual screening by experts in the field, 719 articles and 2580 patents were selected for further analysis.

\subsection{Research methods}

\subsubsection{Bibliometric analysis}

Bibliometric is a quantitative model that analyzes the number of external features of documents (academic documents and patents) and references through mathematical statistics to reveal specific topics (Fahimnia et al., 2015; Zupic and Cater, 2015). In this study, we used frequently-used indicators in bibliometric, such as the number of documents, the number of citations, and the $h$ index, to measure the distribution of PG research strength. Knowledge mapping is an important process of bibliometric, it can represent the status quo of the field and visualize the results (Sun and Zhai, 2018). Citespace, a visualization software coding in Java programming language, was developed to draw a knowledge map of scientific literature and show the development trend in the technical field (Chen, 2004, 2006). Citespace provides a variety of functions to draw knowledge maps. The keyword co-occurrence maps can reflect hotspots of an area, and burst keywords (keywords frequently cited within a period of time) represents cutting-edge topics (Liang et al., 2017).

\subsubsection{Social network analysis}

In recent years, the frequency and importance of scientific cooperation have increased. It has the potential to solve complex scientific problems and is the key to understanding academic exchanges and knowledge dissemination (Sonnenwald, 2007). Social network analysis (SNA) reflects social structural relationships through network nodes and links and focuses on the characteristics of group relationships rather than individuals (Kim et al., 2011). Ucinet software is a well-known and commonly used software for processing social network data (Vital and Martins, 2009). After importing the cooperation data of countries, institutions, and authors obtained in bibliometric into Ucinet, the accompanying software Netdraw can visualize the cooperation network. Subsequently, Ucinet can calculate the degree centrality of each node to reflect the importance of each subject in the network (Dai et al., 2020).

\subsubsection{Technology life cycle theory}

The technology life cycle describes the whole process of a technology from the origin, development, applications, and entering and exiting the market (Liu and Wang, 2010). The S-curve of the Logistic model is commonly used to simulate the technology life cycle of articles and patents (Haupt et al., 2007), in which an analysis tool of the Loglet Lab 4 software is applied to decompose the growth and diffusion patterns into S-shaped logistic components, such as saturation, growth time, and midpoint, to evaluate the development trend of technical fields (Meyer et al., 1999). Saturation is the maximum utility value generated by a certain technology. Growth time is the time for a technology to produce utility value from $10-90 \%$ of the maximum utility value. Midpoint is the turning point of growth and maturity (Franses, 1994).

\section{Result And Discussion}

\subsection{The Basic Status of PG Study}




\subsubsection{The Annual Trends of PG Publications by Countries}

Figure 2 and Fig. 3 respectively plot the annual trends of articles and patents of PG from 1990 to 2020. In general, the development of PGrelated studies is uprising. In terms of total amount, the number of PG patents (2580) is far greater than that in the literatures (719). However, from the perspective of research time, although patents were few before 2006 (none before 1993), there has been a significant rapid development since then. As for the output of each country, it is noteworthy that China has a large proportion in both of articles and patents, especially after 2010. Studies have shown that annual output of PG in China has reached 5 hundred million tons(Zeng et al., 2021), which boosts China to put effort into PG research.

Table 1 and Table 2 show the details of the publications of the top ten countries, such as the total number of documents, total citations, citations per article, and records per capita. In addition, the h-index of each country was calculated to supplement the comprehensive judgment of literature quality. Although China has absolute advantages in total article numbers, total citations and h-index, it does not perform well in terms of average citations per publication and articles per capita. Other countries, such as Spain, India, Brazil, and the United States, have significant performance in indicators that reflect the quality of papers. These countries have made many contributions to the research on the properties and utilization of PG (Campos et al., 2017; Lambert et al., 2018; Luis Guerrero et al., 2020; Nayak et al., 2018). Generally speaking, the regions where PG academic papers are produced are distributed all over the world. In terms of the number of patents (as shown in Table 2), Asian countries such as China, Russia, Kazakhstan, and Belarus are more prominent. Studies have indicated that the main phosphate mine producers and phosphate fertilizers are located in the United States, the former Soviet Union, China, Africa and the Middle East (Tayibi et al., 2009). Therefore, the large production of PG has prompted these countries to accelerate the process of resource recovery through innovative technologies.

Table 1

Articles in the field of PG resource utilization by Country/Region

\begin{tabular}{|c|c|c|c|c|c|c|c|c|c|c|}
\hline Rank & Country/Region & TA & TC & $\begin{array}{l}\text { TC } \\
\text { without } \\
\text { self- } \\
\text { citations }\end{array}$ & SP\% & ACPP & $\begin{array}{l}\text { ACPP } \\
\text { without } \\
\text { self- } \\
\text { citations }\end{array}$ & $\begin{array}{l}\mathrm{H}- \\
\text { index }\end{array}$ & Population & $\begin{array}{l}\text { Records/Population } \\
\left(10^{-8}\right)\end{array}$ \\
\hline 1 & China & 151 & 2084 & 1535 & $21.00 \%$ & 13.80 & 10.17 & 24 & $1,397,715,000$ & 11 \\
\hline 2 & Brazil & 56 & 974 & 878 & $7.79 \%$ & 17.39 & 15.68 & 18 & $211,049,527$ & 27 \\
\hline 3 & USA & 55 & 748 & 701 & $7.65 \%$ & 13.60 & 12.75 & 17 & $328,239,523$ & 17 \\
\hline 4 & Spain & 54 & 1089 & 908 & $7.51 \%$ & 20.17 & 16.81 & 21 & $47,076,781$ & 115 \\
\hline 5 & Poland & 45 & 449 & 391 & $6.26 \%$ & 9.98 & 8.69 & 12 & $37,970,874$ & 119 \\
\hline 6 & India & 37 & 731 & 702 & $5.01 \%$ & 18.94 & 18.17 & 16 & $1,366,417,750$ & 3 \\
\hline 7 & Tunisia & 31 & 297 & 262 & $4.31 \%$ & 9.58 & 8.45 & 9 & $11,694,719$ & 265 \\
\hline 8 & Russia & 29 & 109 & 102 & $4.03 \%$ & 3.76 & 3.52 & 5 & $144,373,535$ & 20 \\
\hline 9 & Egypt & 27 & 459 & 433 & $3.76 \%$ & 17.00 & 16.04 & 12 & $100,388,073$ & 27 \\
\hline 10 & Canada & 24 & 426 & 392 & $3.34 \%$ & 17.75 & 16.33 & 12 & $37,589,262$ & 64 \\
\hline
\end{tabular}


Table 2

Patents in the field of PG resource utilization by Country/Region

\begin{tabular}{|llllll|}
\hline Rank & Country/Region & TP & SP\% & Population & Records/Population $\left(\mathbf{1 0}^{-8}\right)$ \\
\hline 1 & China & 2241 & $86.86 \%$ & $1,397,715,000$ & 160.33 \\
\hline 2 & Russia & 175 & $6.78 \%$ & $144,373,535$ & 121.21 \\
\hline 3 & Kazakhstan & 32 & $1.24 \%$ & $18,513,930$ & 172.84 \\
\hline 4 & WIPO & 31 & $1.20 \%$ & - & - \\
\hline 5 & Belarus & 18 & $0.70 \%$ & $9,466,856$ & 190.14 \\
\hline 6 & Korea & 15 & $0.58 \%$ & $51,709,098$ & 29.01 \\
\hline 7 & India & 13 & $0.50 \%$ & $1,366,417,750$ & 0.95 \\
\hline 8 & Brazil & 11 & $0.43 \%$ & $211,049,527$ & 5.21 \\
\hline 9 & Poland & 9 & $0.35 \%$ & $37,970,874$ & 23.70 \\
\hline 10 & Uzbekistan & 9 & $0.35 \%$ & $33,580,650$ & 26.80 \\
\hline
\end{tabular}

\subsubsection{The Subject Categories of PG Publications}

Based on the subject classification of the ISI Journal Citation Report (JCR), Figure S1 and Figure S2 depict the top ten subjects of PG articles and patents, respectively. Environmental science \& Ecology (254), Engineering (248), Material Science (144), are the top 3 disciplines of PG articles. Moreover, Chemistry (2422), Materials Science (1439), Polymer Science (918) are the top 3 subjects of PG patents. The distribution of subject categories suggested the high priority of environmental, chemical, constructional, and agricultural issues in PG field. In contrast, the subject area of the articles pays more attention to environmental studies, while the patents are more focused on chemical material issues.

\subsubsection{The Distribution of Published Journals of PG articles}

All these 719 articles were published in 260 journals. Table S1 shows the number of articles, journal impact factors, h-index, country of origin, number of citations, etc. of the top 10 journals. The journal with the highest number of publications is "Construction and Building Materials" (40 articles), accounting for $5.56 \%$ of the total, which is 1.38 times that of the second-ranked " Journal of Hazardous Materials" and 1.66 times that of the third-ranked "Journal of Environmental Radioactivity". It can be seen that these are the main carriers of literatures in PG field. In terms of the indicators that measure the quality of journals (impact factor, JCR Partition, $h$ index, citations), half of the journals are located in the first zone of JCR, indicating that the quality of the articles is relatively reliable.

\subsubsection{The Distribution of Institutes of PG Publications}

The top 20 institutions that made the majority of contributions to the total outputs of PG publications are presented in Table S2 and Table S3. Among the top 20 institutions in terms of articles, Universidad de Huelva ranks first, with 41 publications, accounting for $5.7 \%$ of the total. At the second position is Kunming University of Science \& Technology with 32 articles followed by University of Sevilla (28). Moreover, although Council of Scientific \& Industrial Research (India), Instituto de Pesquisas Energeticas e Nucleares (Brazil) and University of Alberta (Canada) do not rank high in the gross, they perform significantly in the indicators such as ACPP without selfcitations and $\mathrm{H}$-index.

Table S3 shows the top 20 assignees, types and countries with patents of PG. Guizhou Kailin Group Co.Ltd. has the greatest number of patents with a total of 208 , accounting for $8.06 \%$. The other institutions with a high number of patents are Guizhou University (143) and Kunming University of Science and Technology (74). As for the type of institutions, enterprises and universities are the main forces in the research and development of PG patents. Amongst the top 20 assignees, seven are placed in Guizhou province, three in Beijing, and two in Hubei and Henan apiece, with significant regional difference due to the origin of PG is mainly produced in southwest China. Different from the distribution of articles, these institutions almost all come from China. This is because China has been increasing the investment in solid waste management to make significant progress in PG reutilization in recent years (Zhang et al., 2019).

\subsection{The Cooperation Situation of PG Study}

Page 5/16 


\subsubsection{Social Network Analysis of Academic Research Groups}

In order to distinctly demonstrate the cooperative relationship in academic research of PG, we selected the countries, institutions and authors with more than 5 articles successively, and then used Ucinet software to conduct co-occurrence analysis on social networks.

In Figure S3, each node represents a country, and the dot size represents the degree centrality, which reflects the influence and importance of the country in the network. The thickness of the line between nodes indicates the number of cooperation between countries. Table S4 lists the top ten countries by degree centrality and their corresponding number rankings. The degree values of France, USA, Tunisia, China and Spain are all more than 20 , indicating that these countries own important positions in the academic research of PG. It is obvious from the thickness of the connection lines in Figure S3 that France and Tunisia, USA and China are two groups of countries that have more cooperation. France and Tunisia have cooperated in the fields of economy, trade, security, and science and technology. Moreover, coastal industries in the Gulf of Gabès in southeastern Tunisia caused hundreds of millions of tons of untreated PG to be discharged into the open sea, causing serious environmental problems (El Zrelli et al., 2018; Sinfort et al., 2019). USA and China are major world powers and have carried out a lot of collaboration in many scientific research areas. It is worth noting that Saudi Arabia and Uzbekistan are also among the top ten countries in Table S4, even if they rank low in the total number of articles. This phenomenon shows that countries with a small volume of publications may also play a role in international cooperation in specific areas.

Consistent with the method in the above, we analyze the institutional cooperation network of research institutions with more than 5 articles. As shown in Figure S4 and Table S5, Universidad de Huelva is the node with the largest degree of centrality, and has a strong cooperative relationship with University of Sevilla, University of Cadiz and Consejo Superior de Investigaciones Cientificas (CSIC). These institutions are located in Spain with a great number of articles, are the main research institutions for PG academic papers. Another obvious cooperating group comes from China, including Guizhou University, Chongqing University, Chinese Academy of Sciences and other institutions. In general, the organizations that cooperate with each other basically belong to the same country. It is not difficult to understand that due to factors such as geographical location and technological level, neighboring institutions have more opportunities to communicate.

Figure S5 and Table S6 respectively show the author's cooperation network and the degree centrality of the top ten authors. There are two main author cooperative groups and several sub-cooperative groups in Figure S5. Similar to the content in Table S5, these authors are from Spain and China. Ranked first is Ma Liping from China, whose degree centrality is as high as 71, accounting for $7.87 \%$, and is the author with the most academic output of PG. Authors ranked second and third place are Yang Jing from China (with 44 degrees, accounting for $4.88 \%$ ) and Perez-Lopez, Rafael from Spain (with 33 degrees, accounting for $3.66 \%$ ), respectively. These top-ranked authors led two major collaboration networks, namely the Chinese group and the Spanish group. In addition, there are some scattered uncomplicated cooperation networks in the map, which shows that the academic research of PG is extensive at the individual level, and the cooperation between individuals is close in a narrow range.

\subsubsection{Social Network Analysis of Applied Research Group}

In order to further explore the cooperation of PG application technologies, we also use ucinet software to plot the cooperation of the assignees sand the inventors of the patents in Figure S6 and Figure S7 severally. There are only a small number of institutions in the assignees cooperation network, as shown in Figure S6. Guizhou Guifu Ecological Fertilizer Co. Ltd., Guizhou Institute of Technology and Guizhou Kexin Chem \& Metallurgy Co. Ltd. are the top three assignees in Table S10, with 38 degrees each, accounting for $24.84 \%$. These three institutions constitute the largest group in the cooperation network. In addition, there are two pairs of partnerships in Figure S6, but compared to the largest, these assignees have less degree centrality. Different from the publication of articles, the special feature of patents lies in their exclusiveness and self-protection. Therefore, it is rare that a patent belongs to two institutions at the same time. However, in actual technology research and development, it is necessary to strengthen exchanges between various institutions, even if they cannot be signed in the same patent.

Figure S7 shows the cooperation network of inventors, which is obviously much more complicated than the map of assignees (Figure S6). The top ten inventors all have a high degree centrality greater than 100 , which proves that there is a strong communication and connection between inventors. This suggests that many of the PG patents involve multiple inventors, that is, the collaboration between patents is concentrated among inventors within the same institution. Compared with the author's cooperation network of the articles (discussed in Sect. 3.2.1), the inventors' communication is concentrated in China, which is an evidence level shows that China plays a significant role in academic research of PG from the individual.

\subsection{The research area of PG Study}

Page 6/16 


\subsubsection{Basic knowledge structure of PG}

When two articles are cited by another article simultaneously, the two articles constitute a co-citation relationship. Co-citation analysis of references is an important method to comprehend the structure, dynamics, and paradigm developments of a given research field (Zupic and Cater, 2015). Figure S8 shows the reference co-citation map of PG literatures with 449 nodes and 1036 links drawn by Citespace software. Each node in the graph represents a cited document, and the size of the node is proportional to the total citation frequency of related documents. The spectra of different colors show the chronological order of the symbiotic relationship between the cited documents: blue indicates the oldest literature, and red indicates the latest. Table $S 9$ lists the top ten articles with co-cited frequency and other details, such as centrality, first author, and publication year. The prominent contributions of the top five co-cited articles in the field of PG were analyzed. The most frequently cited is a study on the radioactivity of PG published by Tayibi, H in 2011. Tayibi (Tayibi et al., 2011) studied the stabilization/solidification process of PG as a building material from the perspective of radioactivity, and obtained a building material with lower radioactivity by mixing PG with a polymeric sulpfur matrix. The second most frequently cited article is researched by Rashad, AM and published in 2015 (Rashad, 2015). The results showed that using a part of PG to replace the fly ash in the alkali-activated fly ash paste can increase the compressive strength and thermal shock resistance of the material. The third study from Yang JK used low autoclave to pretreat the PG, and prepared a kind of load-bearing wall brick that meets the Chinese standard brick size and can replace the traditional fired clay brick (Yang et al., 2009). The fourth place comes from Hentati O's research focused on the effect of PG as a fertilizer on soil biological toxicity (Hentati et al., 2015). The next article from Perez-Lopez, $R$ is to explore the environmental impact of PG piles from the perspective of geochemistry (Perez-Lopez et al., 2016). Generally, the references with the centrality value greater than or equal to 0.1 in Citespace were considered as key publications (Chen, 2006). In Table S9, only the third-ranked Yang JK's article centrality meets this requirement, so it can be considered as a more turning point study. To sum up, these publications all have paid great attention to the application performance and environmental impact of PG or its products from various fields and perspectives and provide the knowledge bases in the field of $P G$ academic research.

In order to further explore the specific knowledge areas involved in these articles, we used the built-in LLR algorithm of Citespace to cluster these articles with keywords. After discriminating the correlation between the labels obtained by clustering and PG research, we screened 9 clusters and displayed their details in Figure S9 and Table S10. Size represents the number of literatures contained in each cluster, namely the measurement of scales. Silhouette score, an indicator of value of homogeneity to evaluate the clusters, is shown in Table S10. These values are generally greater than 0.8 , indicating that the quality of each clustering result is reliable. Mean cited year denotes the average citation time of the documents in the corresponding cluster, which can reflect the time this category has been paid attention to by academia.

It is apparent from Figure S9 and Table S10 that "natural radioactivity", "calcium sulfate" and "soil" are traditional clusters formed before 2010. Generally, PG has a high content of natural radionuclides, especially the decay series of U 238 and Ra 226. Due to these characteristics, PG is considered to be Technologically Enhanced Naturally Occurring Radioactive Materials (TENORM), which has greatly restricted its resource utilization (Moreira et al., 2018). As an inorganic powder material, calcium sulfate whisker (CSW) which has excellent mechanical properties, environmental protection and low price is used as high value-added products of PG. The preparation process of calcium sulfate whiskers mainly focuses on hydrothermal method and atmospheric acidification method, both of which can produce products with high aspect ratio and high purity(Sheng et al., 2018). Besides, PG can exhibit a great deal of advantages as soil amendment in agriculture, such as improving soil physical and chemical properties, supplementing beneficial trace elements, and promoting crop growth. However, the heavy metals and natural radionuclides in PG have prompted studies to pay more attention to its agricultural environmental risks(Wang, 2020). In addition, information of other clusters shows that the basic academic areas of PG are concentrated in cement backfill materials (cluster 3), the preparation of supersulfated cement (cluster 4) and the extraction of rare earth elements (cluster 12). Furthermore, the crystal morphology of PG (cluster 11) has also received a plenty of attention (Jin et al., 2020; Lu et al., 2019; Ru et al., 2012). It is worth noting that cluster 10 "carbon dioxide" and cluster 15 "syngas" are unfamiliar research areas. Studies have shown that the products of PG at high temperatures can capture carbon dioxide (Cardenas-Escudero et al., 2011; Msila et al., 2016; Zhang, W. et al., 2020). This method of synergistic utilization of solid waste resources and carbon emission reduction provides a new perspective for the recovery of PG. Moreover,some scholars use chemical-looping combustion to prepare syngas by using lignite as a carbon source, $P G$ as an oxygen source, and water vapor as a hydrogen source, which makes full use of the calcium sulfate to realize the utilization of PG (Yang et al., 2017; Yang et al., 2018; Yang et al., 2019).

\subsubsection{Hot areas of PG research}

Figure S10 and Figure S11 respectively plot the co-occurrence network map of PG literature keywords and Derwent Manual Code (DMC) from 2018 to 2020 to reflect the hot areas of PG research. The details of the top 20 keywords and DMC in terms of frequency and 
centrality are summarized in Table S11 and Table S12.

Obviously, the keywords "phosphogypsum”, "waste”, “gypsum”, “heavy metal”, "rare earth element”, "hydration”, "water”, "cement”, "soil”, "fly ash" are prominent in the frequency rankings. Centrality values present that "phosphate", "compressive strength", "aqueous solution", "kinetics", "removal", "waste valorization", "sewage sludge", "mortar", "sulfate" and "set retarder" stand out in the rankings. With these information provided in the figures and tables, we divide the academic hotspot research of PG into the following aspects. At the microstructure level, the mechanism of hydration in the chemical process related to PG, the change of crystal structure, and the physical and chemical properties of the product (compressive strength, water resistance, durability etc.) have attracted attention (Gijbels et al., 2019; Haque et al., 2020; Pinto et al., 2020). These studies can fundamentally clarify the characteristics of PG, so as to better promote its resource utilization. On the other hand, due to the peculiarity of PG containing heavy metals and radioactive materials, its environmental impact and safety management of the stacking yard are still continuously becoming academic hotspots (Attallah et al., 2019; RomeroHermida et al., 2020; Tsioka and Voudrias, 2020). Furthermore, the utilization of PG focuses on the extraction of rare earth elements(Jalali et al., 2020), high compressive strength cement (Huang et al., 2019), the preparation of cement retarders and cement mortar(Gong et al., 2020), sludge dewatering (Dai et al., 2018), and co-production with other solid waste(Wang et al., 2020). Compared with the previous section (3.3.1), although there are some overlaps between hot areas and knowledge base, the results of keyword co-occurrence in the past three years provide us with more particular perspectives of the research directions about PG.

In the aspect of DMC frequency, L02-C05 (Calcium sulphate cements), L02-A03 (Refractories, ceramics, cement manufacture - shaping, drying) and A12-R01A (Concrete, cement, gypsum, mortar compositions and boards) rank in the top three. As for centrality, A12-R01A (concrete, cement, gypsum, mortar compositions and boards), L02-D01 (mortars and plasters) A03-A04A (cellulose ethers uses) etc. own the high rankings. In general, the result of DMC co-occurrence believes that the patent hot applications of PG are concentrated in the fields of construction, chemical industry and agriculture. To be specific, refractory materials, ceramics, cement manufacturing, cement additives, surface materials, and cement mortar are the concentrated hot areas of PG patents in construction (Liu et al.; Wang et al., 2020; Xu et al.). In terms of chemical material innovation, in addition to the traditional production of inorganic phosphorus compounds and sulfur compounds, the preparation of composite materials by adding acrylate/cellulose ether has also become a hot topic in PG patents (Bu; Gao; Zhou and Shen). Agricultural DMCs, such as C04-D02, C14-T, C04-A10, etc., also account for a part, mainly focused on preparing compound fertilizers and saline soil amendments to promote plant growth (Chen et al.; Huang et al.).

\subsubsection{Frontier topics of PG research}

Burst keywords represent the words that are cited continually during a certain period and are considered to be indicators of the frontier topics over time. As shown in Table S13 and Table S14, we use Citespace software to detect burst keywords and DMCs from 2018 to 2020 to indicate the frontiers of PG. In particular, we place emphasis on the keywords and DMCs that with longer duration and greater burst strength.

As can be seen from the Table S13, the keywords "recovery", "coal”, "tailing", "stabilization/solidification" and "temperature" possess higher strengths between 2019 and 2020. Masmoudi and Salo innovated the method of recovering rare earth elements from PG (Masmoudi-Soussi et al., 2020; Salo et al., 2020). Due to the complex process and high cost of extracting rare earths from PG, the industrialization of such methods is still facing challenges. Low-cost and high-efficiency rare earth recovery methods still need to be developed. Some scholars have also optimized the methods and conditions of ion solidification/stabilization in PG, which is conducive to the reprocessing and recycling of PG (Li et al., 2019). Temperature, namely reaction conditions, plays a pivotal role in the formation of PG products. Exploring the reaction process and mechanism with different temperature conditions will also be the frontier direction of $P G$ academic research (Lu et al.). Besides, the keywords "mechanism", "durability" and "behavior" also indicates that the research on the physical and chemical properties of substances at the micro level is still the focus of PG in the future (Li et al., 2019; Liu et al., 2020).

Likewise, DMCs such as L02-A08 (Refractories, ceramics, cement - manufacturing methods, equipment - Testing/Control), A12-R07 (Building, civil engineering - Walls, wall coverings and ceilings), L02-D13 (Mortars, concretes - aggregates), A10-E05B (Chemical modification by carbonization) etc. occupy greater burst strengths during 2019-2020. As patents pay more attention to practicability, part of the development trend of PG patented technology is the improvement of equipment manufacturing, such as innovations in crushing sorting devices and calcining and drying devices (Zhou et al.; Zhu). In the preparation of building materials, the innovative wall materials (gypsum plasterboard, gypsum block, cement concrete, silicate concrete, etc.) not only reduce the use of high-energy clay brick to cut down the production costs, but also can solve the problem of large accumulation of PG (Gong and Shi; Jiang et al.; Yin et al.; Zhou et al.). There are also some DMCs (A10-E21A, A10-E12A, A10-E05B) in the table indicating chemical modification of various methods, since the 
preparation of PG products involves many chemical processes, it is more likely to prepare innovative polymer materials (Shen et al.; Su et al.).

\subsection{Prediction of research trend of PG}

In order to quantitatively and accurately predict the growth trend of documents in various fields of PG, we merged articles with similar meanings of subject categories (such as classifying architecture, construction \& building technology, and engineering as construction engineering), and summarized them as four categories, that are, constructional engineering, chemical materials, environmental science and agricultural science. The technical life cycle curve of the PG articles, the S-curves, drawn by the Loglet Lab4 software, where the blue dots in the figure represents the actual cumulative number of $P G$ articles each year, and the blue line is the fitting curve between the actual and the predicted numbers, as shown in Figure S12. The specific parameters and growth stage details are shown in Table S15 and Table S16. Among the four categories, "Constructional Engineering" has the highest Saturation value (324), which means it will owe a broad development space. On the contrary, the Saturation value of "Agricultural Science" is only 111, which means that the future of PG academic papers in agriculture will not increase drastically. The growth time value and midpoint value can be used to divide the technology life cycle stages, and the results are summarized in Table 18. From the perspective of the timing of the stages, the four types of technology categories are currently in the maturity. The three major categories of "Constructional Engineering", "Chemical Materials" and "Environmental Science" will enter the decline stage in 2033, 2031, and 2033, respectively. What stands out in Table 18 is the forthcoming decline of the category of "Agricultural Science", approximately after 2025. To sum up, both in terms of the number of articles and the stage time, "Construction Engineering" has the most application prospects, followed by "Chemical Materials" and "Environmental Science", but there is not much room for the development of "Agricultural Science".

Similarly, we also counted the annual distribution of the top four categories of the DMCs in the patents, namely L (Refractories, Glass, Ceramics), A (Polymers, Plastics), C (Agricultural Chemicals) and E (General Chemicals). Figure S13 plots the S-curve of each technical field of the patents. The specific results are shown in Table S17 and Table S18. It can be seen from the value of Saturation that Lcategory will have the largest number of accumulated patents, followed by A-category, C-category and E-category. While from the value of Growth time, it can be judged that L-category has the longest development time, while A-category has the shortest. In terms of the stage of the technology life cycle (Table S18), it is considered that L-category is in the development period, A-category is in the decline period, and C-category and E-category are in the mature period. Taken together, the future prospect of the distribution of PG patents in L (Refractories, Glass, Ceramics) is the largest and the development time is still very long. C (Agricultural Chemicals) and E (General Chemicals) are basically the same, but there is almost no more space in the A (Polymers, Plastics) category to blossom.

\section{Conclusion}

This study conducted a bibliometric analysis of the articles and patents of PG in the web of science from 1990 to 2020 . The key findings are summarized as follows.

(1) Firstly, the basic status shows that the number of patents for PG is far greater than the number of articles. In terms of the quantity of national output, China has an absolute advantage in both articles and patents, but Spain, Brazil, India and the United States perform better in a great part of indicators that reflect the quality of the literatures. The subjects of the articles pay more attention to environmental studies, while the patents are more focused on chemical material issues. The journal, Construction and Building Materials, ranks first among the PG-related journals. Universidad de Huelva and Guizhou Kailin Group Co. Ltd. are the institutions that produce the most articles and patents respectively. The distribution of assignees presents a strong geographically characteristic, that is, many are located in Guizhou Province, China. (2) Secondly, the results of social network analysis believe that France, USA, Tunisia and China play a leading role in the international cooperation of PG. At institutional and author's levels of academic articles, there are mainly cooperative groups represented by Spain and China respectively. Due to the particularity of patents, the cooperation of assignees and inventors is different from academic articles, namely little connection between institutions but a lot in inventors. (3) Furthermore, the reference cocitation analysis indicates that the knowledge base in the field of PG research is concentrated in the fields of natural radioactivity, cemented paste backfill, soil, carbon dioxide, crystal morphology, syngas, etc. According to the results of the co-occurrence analysis of keywords from 2018 to 2020, the academic hotspots are concentrated on the study of the microstructure in the chemical process, the environmental impact of heavy metals and radioactive substances, and application research such as rare earth elements extraction, preparation of cement products, dewatering of sludge and combined utilization with other solid waste. The co-occurrence results of DMCs indicate that the hot spot of the patents is the production of refractory materials, ceramics, surface materials, cement mortar, and composite materials by adding acrylate/cellulose etc. Regarding the research frontiers, burst keywords show that the academic frontier of PG will be the methods of recovering rare earth elements from PG, the conditions of ion solidification/stabilization in PG, the impact of

Page 9/16 
reaction conditions on product quality, and the micro-level reaction mechanism and physical and chemical properties. On the other hand, the forefront of patents will focus on the improvement of manufacturing equipment, the innovation of new wall materials and chemically modified polymer materials. (4) Finally, the technical life cycle S-curves of the various sub-fields of the articles and patents mean that "construction engineering" and L (Refractories, Glass, Ceramics) have the largest application prospects, but "agricultural science" and A (Polymers, Plastics) have the most narrow development space.

In conclusion, this study provides an insight into the publications for PG and valuable information for researchers to identify new perspectives concerning potential partners, cooperative institutions, knowledge structure, research hotspots and frontiers. Although we have obtained many valuable conclusions about the academic and applied research of PG, the key factors restricting the resource utilization of PG are still the directions worthy of discussion in the future. Researchers should not only be keen on theoretically innovative research, but also pay attention to the possibility of technological application. Further work needs to be carried out to widely promote technologies and products with wide applicability and high added value to form a circular economy chain using PG.

\section{Declarations}

\section{Ethics approval and consent to participate}

Not applicable.

\section{Consent for publication}

Not applicable.

\section{Availability of data and materials}

The datasets used and analysed during the current study are available from the corresponding author on reasonable request.

\section{Competing interests}

The authors declare that they have no competing interests.

\section{Funding}

This research is supported by National Key R\&D Program of China (2018YFC1903604).

\section{Authors' contributions}

C YM: Methodology, Data collection and processing, Writing - Original Draft, Writing - Review \& Editing. C Y: Data collection and processing, Visualization, Writing - Review \& Editing. Y XK: Data collection and processing, Visualization. L T: Writing - review \& editing. C IS: Supervision. W J: Conceptualization, Supervision

All authors read and approved the final manuscript.

\section{Acknowledgements}

This research is supported by National Key R\&D Program of China (2018YFC1903604).

\section{References}

1. Attallah, M.F., Metwally, S.S., Moussa, S.I., Soliman, M.A., 2019. Environmental impact assessment of phosphate fertilizers and phosphogypsum waste: Elemental and radiological effects. Microchem J. 146, 789-797. http://doi.org/10.1016/j.microc.2019.02.001.

2. Beretka, J., Devito, B., Santoro, L., Sherman, N., Valenti, G.L., 1993. Utilisation of industrial wastes and by-products for the synthesis of special cements. Resour. Conserv. Recycl. 9(3), 179-190. http://doi.org/10.1016/0921-3449(93)90002-w.

3. Bu, X., Lightweight and environmentally friendly wall material comprises e.g. phosphogypsum, iron, styrene-acrylate emulsion, magnesium chloride, fly ash, kieselguhr, kaolin, water reducing agent, methylhydroxyethyl cellulose, cement, and water. HUAXIN NEW WALL MATERIALS WUXUE CO LTD (HUAX-Non-standard).

Page $10 / 16$ 
4. Campos, M.P., Costa, L.J.P., Nisti, M.B., Mazzilli, B.P., 2017. Phosphogypsum recycling in the building materials industry: assessment of the radon exhalation rate. J. Environ. Radioact. 172, 232-236. http://doi.org/10.1016/j.jenvrad.2017.04.002.

5. Cardenas-Escudero, C., Morales-Florez, V., Perez-Lopez, R., Santos, A., Esquivias, L., 2011. Procedure to use phosphogypsum industrial waste for mineral CO2 sequestration. J. Hazard. Mater. 196, 431-435. http://doi.org/10.1016/j.jhazmat.2011.09.039.

6. Chen, C.M., 2004. Searching for intellectual turning points: Progressive knowledge domain visualization. Proceedings of the National Academy of Sciences of the United States of America 101, 5303-5310. http://doi.org/10.1073/pnas.0307513100.

7. Chen, C.M., 2006. CiteSpace II: Detecting and visualizing emerging trends and transient patterns in scientific literature. J. Am. Soc. Inf. Sci. Technol. 57(3), 359-377. http://doi.org/10.1002/asi.20317.

8. Chen, L., He, Y., Shen, L., Chemical additive useful for repairing heavy metal contaminated land, comprises high alumina cement, quicklime, phosphogypsum, kaolin, sodium sulfide, iron sulfate, magnesium-containing preparation, apatite, and calcium oxide. HUNAN TAIHUA TECHNOLOGY MONITORING CO (HUNA-Non-standard).

9. Chen, Q.S., Zhang, Q.L., Qi, C.C., Fourie, A., Xiao, C.C., 2018. Recycling phosphogypsum and construction demolition waste for cemented paste backfill and its environmental impact. J. Cleaner Prod. 186(JUN.10), 418-429. http://doi.org/10.1016/j.jclepro.2018.03.131.

10. Dai, Q.X., Ma, L.P., Ren, N.Q., Ning, P., Guo, Z.Y., Xie, L.G., Gao, H.J., 2018. Investigation on extracellular polymeric substances, sludge flocs morphology, bound water release and dewatering performance of sewage sludge under pretreatment with modified phosphogypsum. Water Res. 142, 337-346. http://doi.org/10.1016/j.watres.2018.06.009.

11. Dai, S.L., Duan, X., Zhang, W., 2020. Knowledge map of environmental crisis management based on keywords network and co-word analysis, 2005-2018. J. Cleaner Prod. 262, 8. http://doi.org/10.1016/j.jclepro.2020.121168.

12. El Zrelli, R., Rabaoui, L., Daghbouj, N., Abda, H., Castet, S., Josse, C., van Beek, P., Souhaut, M., Michel, S., Bejaoui, N., Courjault-Rade, P., 2018. Characterization of phosphate rock and phosphogypsum from Gabes phosphate fertilizer factories (SE Tunisia): high mining potential and implications for environmental protection. Environ. Sci. Pollut. Res. 25(15), 14690-14702. http://doi.org/10.1007/s11356-018-1648-4.

13. Fahimnia, B., Sarkis, J., Davarzani, H., 2015. Green supply chain management: A review and bibliometric analysis. Int. J. Prod. Econ. 162, 101-114. http://doi.org/10.1016/j.ijpe.2015.01.003.

14. Franses, P.H., 1994. A method to select between Gompertz and logistic trend curves. Technol. Forecast. Soc. Chang. 46(1), 45-49. http:// doi.org/10.1016/0040-1625(94)90016-7.

15. Gao, R., Phosphogypsum slurry useful for wall plastering comprises phosphogypsum, rubber powder, sand, water and cellulose. China Mcc17 Group Co Ltd (Cmeg-C).

16. Gijbels, K., Nguyen, H., Kinnunen, P., Schroeyers, W., Pontikes, Y., Schreurs, S., Illikainen, M., 2019. Feasibility of incorporating phosphogypsum in ettringite-based binder from ladle slag. J. Cleaner Prod. 237, 10. http://doi.org/10.1016/j.jclepro.2019.117793.

17. Gong, P., Shi, N., Modified phosphogypsum-based concrete prefabricated component comprises phosphogypsum, quicklime, cement, water, water reducing agent, glass fiber, fly ash, sand, and stone and prepared by mixing hosphogypsum and pre-hydrating quicklime. NANTONG GREATWALL CONSTR TECHNOLOGY CO (NANT-Non-standard).

18. Gong, X.Q., Liu, J.S., Zhang, T.T., Jiao, Z., 2020. Effect of Modified Phosphogypsum on Properties of Cement Mortar. J. Test. Eval. 48(4), 2803-2812. http://doi.org/10.1520/jte20180702.

19. Gu, K., Chen, B., Pan, Y., 2020. Utilization of untreated-phosphogypsum as filling and binding material in preparing grouting materials. Constr. Build. Mater. 265. http://doi.org/10.1016/j.conbuildmat.2020.120749.

20. Guerrero, J.L., Perez-Moreno, S.M., Gutierrez-Alvarez, I., Gazquez, M.J., Bolivar, J.P., 2021. Behaviour of heavy metals and natural radionuclides in the mixing of phosphogypsum leachates with seawater. Environ. Pollut. 268(Pt A), 115843. http://doi.org/10.1016/j.envpol.2020.115843.

21. Haque, M.A., Chen, B., Liu, Y.T., Shah, S.F.A., Ahmad, M.R., 2020. Improvement of physico-mechanical and microstructural properties of magnesium phosphate cement composites comprising with Phosphogypsum. J. Cleaner Prod. 261, 15. http://doi.org/10.1016/j.jclepro.2020.121268.

22. Haupt, R., Kloyer, M., Lange, M., 2007. Patent indicators for the technology life cycle development. Res. Policy 36(3), $387-398$. http://doi.org/10.1016/j.respol.2006.12.004.

23. Hentati, O., Abrantes, N., Caetano, A.L., Bouguerra, S., Goncalves, F., Roembke, J., Pereira, R., 2015. Phosphogypsum as a soil fertilizer: Ecotoxicity of amended soil and elutriates to bacteria, invertebrates, algae and plants. J. Hazard. Mater. 294, 80-89. http://doi.org/10.1016/j.jhazmat.2015.03.034. 
24. Huang, T., Song, D., Zhang, S., Liu, L., Zhou, L., Tao, J., Xu, J., Additive useful for preparing soil improvement agent comprises humus, tuff, phosphogypsum, iron powder and aluminum powder. Changshu Inst Technology (Chgs-C).

25. Huang, Y.B., Qian, J.S., Kang, X.J., Yu, J.C., Fan, Y.R., Dang, Y.D., Zhang, W.S., Wang, S.D., 2019. Belite-calcium sulfoaluminate cement prepared with phosphogypsum: Influence of $\mathrm{P}_{2} \mathrm{O}_{5}$ and $\mathrm{F}$ on the clinker formation and cement performances. Constr. Build. Mater. 203, 432-442. http://doi.org/10.1016/j.conbuildmat.2019.01.112.

26. Jalali, J., Gaudin, P., Ammar, E., Lebeau, T., 2020. Bioaugmentation coupled with phytoextraction for the treatment of Cd and Sr, and reuse opportunities for phosphogypsum rare earth elements. J. Hazard. Mater. 399, 11. http://doi.org/10.1016/j.jhazmat.2020.122821.

27. Jiang, Z., Zhong, Y., Chen, Q., High water-resistant non-calcined phosphogypsum-based slope block material comprises e.g. phosphogypsum component, slag component, cement component, fine aggregate, coarse aggregate, water reducer component and waterproof component. Univ Tongji (Uytj-C).

28. Jin, Z.H., Ma, B.G., Su, Y., Lu, W.D., Qi, H.H., Hu, P.H., 2020. Effect of calcium sulphoaluminate cement on mechanical strength and waterproof properties of beta-hemihydrate phosphogypsum. Constr. Build. Mater. 242, 10. http://doi.org/10.1016/j.conbuildmat.2020.118198.

29. Kim, Y., Choi, T.Y., Yan, T.T., Dooley, K., 2011. Structural investigation of supply networks: A social network analysis approach. J. Oper. Manag. 29(3), 194-211. http://doi.org/10.1016/j.jom.2010.11.001.

30. Lambert, A., Anawati, J., Walawalkar, M., Tam, J., Azimi, G., 2018. Innovative Application of Microwave Treatment for Recovering of Rare Earth Elements from Phosphogypsum. ACS Sustain. Chem. Eng. 6(12), 16471-16481. http://doi.org/10.1021/acssuschemeng.8b03588.

31. Li, B., Shu, J.C., Yang, L., Tao, C.Y., Chen, M.J., Liu, Z.H., Liu, R.L., 2019. An innovative method for simultaneous stabilization/solidification of P043- and F- from phosphogypsum using phosphorus ore flotation tailings. J. Cleaner Prod. 235, 308316. http://doi.org/10.1016/j.jclepro.2019.06.340.

32. Li, X.B., Zhou, S.T., Zhou, Y.N., Min, C.D., Cao, Z.W., Du, J., Luo, L., Shi, Y., 2019. Durability Evaluation of Phosphogypsum-Based Cemented Backfill Through Drying-Wetting Cycles. Minerals 9(5), 13. http://doi.org/10.3390/min9050321.

33. Liang, Y.-D., Li, Y., Zhao, J., Wang, X.-Y., Zhu, H.-Z., Chen, X.-H., 2017. Study of acupuncture for low back pain in recent 20 years: a bibliometric analysis via CiteSpace. J. Pain Res. 10, 951-964. http://doi.org/10.2147/.jpr.S132808.

34. Liu, C.-Y., Wang, J.-C., 2010. Forecasting the development of the biped robot walking technique in Japan through S-curve model analysis. Scientometrics 82(1), 21-36. http://doi.org/10.1007/s11192-009-0055-5.

35. Liu, S.H., Fang, P.P., Ren, J., Li, S.F., 2020. Application of lime neutralised phosphogypsum in supersulfated cement. J. Cleaner Prod. 272, 10. http://doi.org/10.1016/j.jclepro.2020.122660.

36. Liu, W., Liao, H., 2017. A Bibliometric Analysis of Fuzzy Decision Research During 1970-2015. Int. J. Fuzzy Syst. 19(1), 1-14. http://doi.org/10.1007/s40815-016-0272-z.

37. Liu, Y., Qiao, D., He, F., Su, L., Liu, Z., Yang, Q., Pan, Z., Xia, Y., Qin, Z., Zhang, J., Ao, Q., Gong, G., Wang, X., Zhu, X., Cheng, Y., Preparing industrial solid waste composite material brick used in building material, involves preparing fine particles of phosphorus residue and steel residue, grinding, stirring products with phosphogypsum and alkali activator and steaming. GUIZHOU HONGXIN CHUANGDA ENG DETECTION (GUIZ-Non-standard).

38. Lu, D.H., Chen, Q.L., Li, C.Q., Gong, S., Effect of potassium feldspar on the decomposition rate of phosphogypsum. J. Chem. Technol. Biotechnol., 10. http://doi.org/10.1002/jctb.6549.

39. Lu, W.D., Ma, B.G., Su, Y., He, X.Y., Jin, Z.H., Qi, H.H., 2019. Preparation of alpha-hemihydrate gypsum from phosphogypsum in recycling $\mathrm{CaCl}_{2}$ solution. Constr. Build. Mater. 214, 399-412. http://doi.org/10.1016/j.conbuildmat.2019.04.148.

40. Luis Guerrero, J., Gutierrez-Alvarez, I., Mosqueda, F., Jesus Gazquez, M., Garcia-Tenorio, R., Olias, M., Pedro Bolivar, J., 2020. Evaluation of the radioactive pollution in the salt-marshes under a phosphogypsum stack system. Environ. Pollut. 258. http://doi.org/10.1016/j.envpol.2019.113729.

41. Lv, P.H., Wang, G.-F., Wan, Y., Liu, J., Liu, Q., Ma, F.-c., 2011. Bibliometric trend analysis on global graphene research. Scientometrics 88(2), 399-419. http://doi.org/10.1007/s11192-011-0386-X.

42. Masmoudi-Soussi, A., Hammas-Nasri, I., Horchani-Naifer, K., Ferid, M., 2020. Rare earths recovery by fractional precipitation from a sulfuric leach liquor obtained after phosphogypsum processing. Hydrometallurgy 191, 8. http://doi.org/10.1016/j.hydromet.2020.105253. 
43. Meyer, P.S., Yung, J.W., Ausubel, J.H., 1999. A primer on logistic growth and substitution - The mathematics of the Loglet Lab software. Technol. Forecast. Soc. Chang. 61(3), 247-271. http://doi.org/10.1016/s0040-1625(99)00021-9.

44. Millan-Becerro, R., Perez-Lopez, R., Macias, F., Canovas, C.R., 2020. Design and optimization of sustainable passive treatment systems for phosphogypsum leachates in an orphan disposal site. J. Environ. Manag. 275, 111251. http://doi.org/10.1016/j.jenvman.2020.111251.

45. Mohammed, F., Biswas, W.K., Yao, H., Tadé, M., 2018. Sustainability assessment of symbiotic processes for the reuse of phosphogypsum. J. Cleaner Prod. 188, 497-507. http://doi.org/10.1016/j.jclepro.2018.03.309.

46. Moreira, R.H., Queiroga, F.S., Paiva, H.A., Medina, N.H., Fontana, G., Guazzelli, M.A., 2018. Extraction of natural radionuclides in TENORM waste phosphogypsum. J. Environ. Chem. Eng. 6(5), 6664-6668. http://doi.org/10.1016/j.jece.2018.10.019.

47. Msila, X., Billing, D.G., Barnard, W., 2016. Capture and storage of $\mathrm{CO}_{2}$ into waste phosphogypsum: the modified Merseburg process. Clean Technol. Environ. Policy 18(8), 2709-2715. http://doi.org/10.1007/s10098-016-1157-4.

48. Nayak, S., Mishra, C.S.K., Guru, B.C., Samal, S., 2018. Histological anomalies and alterations in enzyme activities of the earthworm Glyphidrillus tuberosus exposed to high concentrations of phosphogypsum. Environ. Monit. Assess. 190(9). http://doi.org/10.1007/s10661-018-6933-7.

49. Peng, B., Guo, D., Qiao, H., Yang, Q., Zhang, B., Hayat, T., Alsaedi, A., Ahmad, B., 2018. Bibliometric and visualized analysis of China's coal research 2000-2015. J. Cleaner Prod. 197, 1177-1189. http://doi.org/10.1016/j.jclepro.2018.06.283.

50. Pérez-López, R., Macías, F., Cánovas, C.R., Sarmiento, A.M., Pérez-Moreno, S.M., 2016. Pollutant flows from a phosphogypsum disposal area to an estuarine environment: An insight from geochemical signatures. Sci. Total Environ. 553, $42-51$. http://doi.org/10.1016/j.scitotenv.2016.02.070.

51. Perez-Lopez, R., Macias, F., Ruiz Canovas, C., Miguel Sarmiento, A., Maria Perez-Moreno, S., 2016. Pollutant flows from a phosphogypsum disposal area to an estuarine environment: An insight from geochemical signatures. Sci. Total Environ. 553, $42-51$. http://doi.org/10.1016/j.scitotenv.2016.02.070.

52. Pinto, S.R., da Luz, C.A., Munhoz, G.S., Medeiros, R.A., 2020. Durability of phosphogypsum-based supersulfated cement mortar against external attack by sodium and magnesium sulfate. Cem. Concr. Res. 136, 19. http://doi.org/10.1016/j.cemconres.2020.106172.

53. Qamouche, K., Chetaine, A., Elyahyaoui, A., Moussaif, A., Touzani, R., Benkdad, A., Amsil, H., Laraki, K., Marah, H., 2020. Radiological characterization of phosphate rocks, phosphogypsum, phosphoric acid and phosphate fertilizers in Morocco: An assessment of the radiological hazard impact on the environment. Materials Today: Proceedings 27, 3234-3242. http://doi.org/10.1016/j.matpr.2020.04.703.

54. Rashad, A.M., 2015. Potential use of phosphogypsum in alkali-activated fly ash under the effects of elevated temperatures and thermal shock cycles. J. Cleaner Prod. 87, 717-725. http://doi.org/10.1016/j.jclepro.2014.09.080.

55. Romero-Hermida, M.I., Flores-Ales, V., Hurtado-Bermudez, S.J., Santos, A., Esquivias, L., 2020. Environmental Impact of Phosphogypsum-Derived Building Materials. Int. J. Environ. Res. Public Health 17(12), 17. http://doi.org/10.3390/ijerph17124248.

56. Ru, X.H., Ma, B.G., Huang, J., Huang, Y., 2012. Phosphogypsum Transition to alpha-Calcium Sulfate Hemihydrate in the Presence of Omongwaite in NaCl Solutions Under Atmospheric Pressure. J. Am. Ceram. Soc. 95(11), 3478-3482. http://doi.org/10.1111/j.15512916.2012.05429.x.

57. Salo, M., Knauf, O., Makinen, J., Yang, X.S., Koukkari, P., 2020. Integrated acid leaching and biological sulfate reduction of phosphogypsum for REE recovery. Miner. Eng. 155, 7. http://doi.org/10.1016/j.mineng.2020.106408.

58. Shen, C., Yang, M., Chen, K., Preparing high-strength water-resistant autoclaved brick comprises e.g. mixing phosphogypsum and quicklime to obtain mixture, spraying with water mist, allowing to stand, grinding and discharging to obtain modified phosphogypsum powder. FOSHAN JIUMO TECHNOLOGY INFORMATION CONS (FOSH-Non-standard).

59. Sheng, Z., Zhou, J., Shu, Z., Yakubu, Y., Chen, Y., Wang, W., Wang, Y., 2018. Calcium sulfate whisker reinforced non-fired ceramic tiles prepared from phosphogypsum. Boletín de la Sociedad Española de Cerámica y Vidrio 57(2), 73-78. http://doi.org/10.1016/j.bsecv.2017.09.005.

60. Sinfort, C., Perignon, M., Drogue, S., Amiot, M.J., 2019. Dataset on potential environmental impacts of water deprivation and land use for food consumption in France and Tunisia. Data in Brief 27, 104661-Article No.: 104661. http://doi.org/10.1016/j.dib.2019.104661.

61. Sonnenwald, D.H., 2007. Scientific collaboration. Annu. Rev. Inform. Sci. Technol. 41, 643-68. http://doi.org/10.1002/aris.2007.1440410121. 
62. Su, Y., Xiong, G., Lu, F., He, X., Chen, S., Chen, W., Yang, J., Wang, Y., Huang, Z., Liu, Q., Jiang, Y., Preparing phosphogypsum slurry material comprises mixing phosphogypsum hemihydrate powder, modified nano-phosphogypsum powder, fumed silica, nanoalumina aerogel powder, gypsum activator and water, and stirring. Univ Hubei Technology (Uyhi-C).

63. Sun, Y., Zhai, Y., 2018. Mapping the knowledge domain and the theme evolution of appropriability research between 1986 and 2016 : a scientometric review. Scientometrics 116(1), 203-230. http://doi.org/10.1007/s11192-018-2748-0.

64. Tayibi, H., Choura, M., Lopez, F.A., Alguacil, F.J., Lopez-Delgado, A., 2009. Environmental impact and management of phosphogypsum. J. Environ. Manage. 90(8), 2377-2386. http://doi.org/10.1016/j.jenvman.2009.03.007.

65. Tayibi, H., Gasco, C., Navarro, N., Lopez-Delgado, A., Alvarez, A., Yaguee, L., Alguacil, F.J., Lopez, F.A., 2011. Valorisation of phosphogypsum as building material: radiological aspects. Mater. Constr. 61(304), 503-515. http://doi.org/10.3989/mc.2010.58910.

66. Tsioka, M., Voudrias, E.A., 2020. Comparison of alternative management methods for phosphogypsum waste using life cycle analysis. J. Cleaner Prod. 266, 12. http://doi.org/10.1016/j.jclepro.2020.121386.

67. Vasconez-Maza, M.D., Bueso, M.C., Faz, A., Acosta, J.A., Martinez-Segura, M.A., 2021. Assessing the behaviour of heavy metals in abandoned phosphogypsum deposits combining electrical resistivity tomography and multivariate analysis. J. Environ. Manag. 278(Pt 1), 111517. http://doi.org/10.1016/j.jenvman.2020.111517.

68. Vital, C., Martins, E.P., 2009. Using Graph Theory Metrics to Infer Information Flow Through Animal Social Groups: A Computer Simulation Analysis. Ethology 115(4), 347-355. http://doi.org/10.1111/j.1439-0310.2009.01613.x.

69. Wang, C.Q., Mei, X.D., Zhang, C., Liu, D.S., Xu, F.L., 2020. Mechanism study on co-processing of water-based drilling cuttings and phosphogypsum in non-autoclaved aerated concrete. Environ. Sci. Pollut. Res. 27(18), 23364-23368. http://doi.org/10.1007/s11356020-09029-z.

70. Wang, J.M., 2020. Utilization effects and environmental risks of phosphogypsum in agriculture: A review. J. Cleaner Prod. 276. http://doi.org/10.1016/j.jclepro.2020.123337.

71. Wang, X.W., Zhang, X., Xu, S.M., 2011. Patent co-citation networks of Fortune 500 companies. Scientometrics 88(3), 761-770. http://doi.org/10.1007/s11192-011-0414-x.

72. Xu, H., He, Z., Yang, B., Zhang, Q., An, G., Peng, B., Song, W., Xu, W., Li, G., Zhu, G., Yang, Y., Yao, M., Wei, M., Wang, Q., Zhang, Y., Shi, H., Mi, L., Liu, X., Luo, J., Cui, J., Preparing high-strength lightweight keel comprises performing gypsum pretreatment, calcination, and shaping of phosphogypsum, polypropylene fiber, water reducing agent, and strengthening materials. Guizhou Kailin Ardealite Comprehensive (Guiz-C).

73. Yang, J., Ma, L.P., Dong, S.L., Liu, H.P., Zhao, S.Q., Cui, X.J., Zheng, D.L., Yang, J., 2017. Theoretical and experimental demonstration of lignite chemical looping gasification of phosphogypsum oxygen carrier for syngas generation. Fuel 194, 448-459. http://doi.org/10.1016/j.fuel.2016.12.077.

74. Yang, J., Ma, L.P., Zheng, D.L., Zhao, S.Q., Peng, Y.H., 2018. Reaction Mechanism for Syngas Preparation by Lignite Chemical Looping Gasification Using Phosphogypsum Oxygen Carrier. Energy Fuels 32(7), 7857-7867. http://doi.org/10.1021/acs.energyfuels.8b01112.

75. Yang, J., Wei, Y., Yang, J., Xiang, H.P., Ma, L.P., Zhang, W., Wang, L.C., Peng, Y.H., Liu, H.P., 2019. Syngas production by chemical looping gasification using Fe supported on phosphogypsum compound oxygen carrier. Energy 168, 126-135. http://doi.org/10.1016/j.energy.2018.11.106.

76. Yang, J.K., Liu, W.C., Zhang, L.L., Xiao, B., 2009. Preparation of load-bearing building materials from autoclaved phosphogypsum. Constr. Build. Mater. 23(2), 687-693. http://doi.org/10.1016/j.conbuildmat.2008.02.011.

77. Yin, D., Wang, P., Tan, D., Jian, M., Machine spraying heat preservation layer plastering gypsum comprises pre-treated phosphogypsum and accelerator and prepared by pretreating phosphogypsum and adjusting the pH of phosphogypsum to neutral or weakly alkaline, calcinating. Beijing New Building Material Gen Factor (Chnb-C).

78. Zeng, L.L., Bian, X., Zhao, L., Wang, Y.J., Hong, Z.S., 2021. Effect of phosphogypsum on physiochemical and mechanical behaviour of cement stabilized dredged soil from Fuzhou, China. Geomech. Energy Environ. 25, 100195. http://doi.org/10.1016/j.gete.2020.100195.

79. Zhang, G.P., Shi, Q., Li, Q.N., Wang, H.T., Yuan, H.Y., Guo, W.J., Lu, Y.F., 2020. Agents for sludge dewatering in fundamental research and applied research: A bibliometric analysis. J. Cleaner Prod. 273. http://doi.org/10.1016/j.jclepro.2020.122907.

80. Zhang, W., Zhang, F.Z., Ma, L.P., Yang, J., Wei, Y., Kong, D.Q., 2020. $\mathrm{CO}_{2}$ capture and process reinforcement by hydrolysate of phosphogypsum decomposition products. J. $\mathrm{CO}_{2}$ Util. 36, 253-262. http://doi.org/10.1016/j.jcou.2019.11.020. 
81. Zhang, W., Zhang, W.R., 2018. Knowledge creation through industry chain in resource-based industry: case study on phosphorus chemical industry chain in western Guizhou of China. J. Knowl. Manag. 22(5), 1037-1060. http://doi.org/10.1108/jkm-02-2017-0061.

82. Zhou, L., Huang, Y., Chen, B., Zhang, C., Method for manufacturing cold-formed thin-walled C-shaped steel edging phosphogypsum module filling wall, involves injecting polyurethane foam into gap between top of wall and bottom of beam, and completing construction of wall structure. Univ Guizhou (Uygz-C).

83. Zhou, L., Ma, H., Su, Q., Zeng, Y., Mo, F., Zhao, Y., Phosphogypsum pretreatment device comprises first grade rinsing pool, secondary rinsing pool and washing pool, where first grade rinsing pool, secondary rinsing and washing pool are arranged from left to right and separated by clapboard. Univ Guilin Technology at Nanning (Uygi-C).

84. Zhou, P., Shen, P., Building putty powder thickening material comprises phosphogypsum, fly ash, cellulose ether, redispersible latex powder, water reducing agent, etherified starch and antifungal agent. GUANGDONG YUEGU BUILDING MATERIAL TECHNO (GUANNon-standard).

85. Zhu, X., Pretreatment system useful for industrial phosphogypsum, comprises e.g. control and management of the phosphogypsum entering the field includes the setting of the control items and detection methods. GUIZHOU SANDU SOUTHWEST CEMENT CO LTD (GUIZ-Non-standard).

86. Zupic, l., Cater, T., 2015. Bibliometric Methods in Management and Organization. Organ. Res. Methods 18(3), $429-472$. http://doi.org/10.1177/1094428114562629.

\section{Figures}

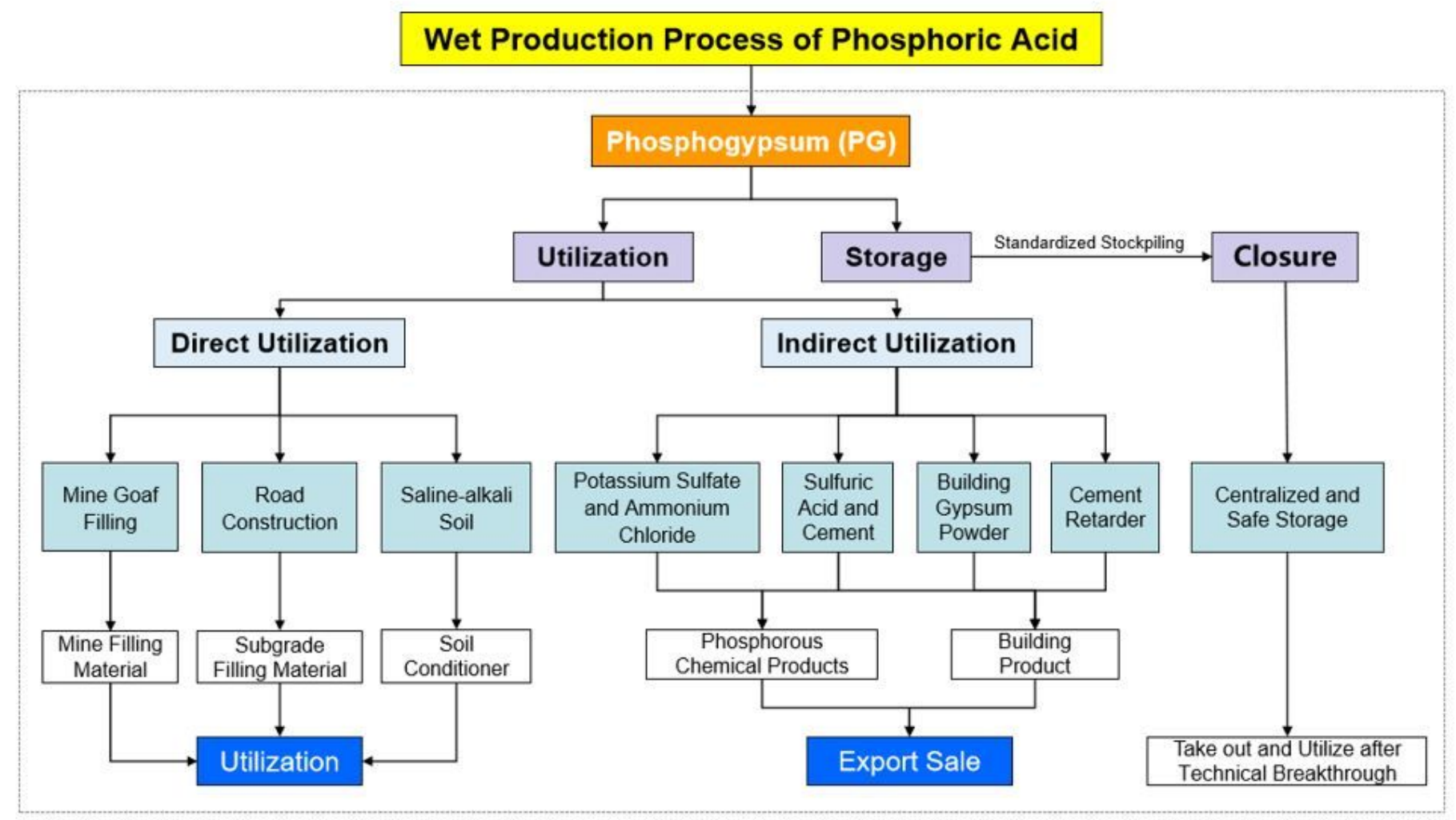

Figure 1

Main treatment and utilization methods of PG 


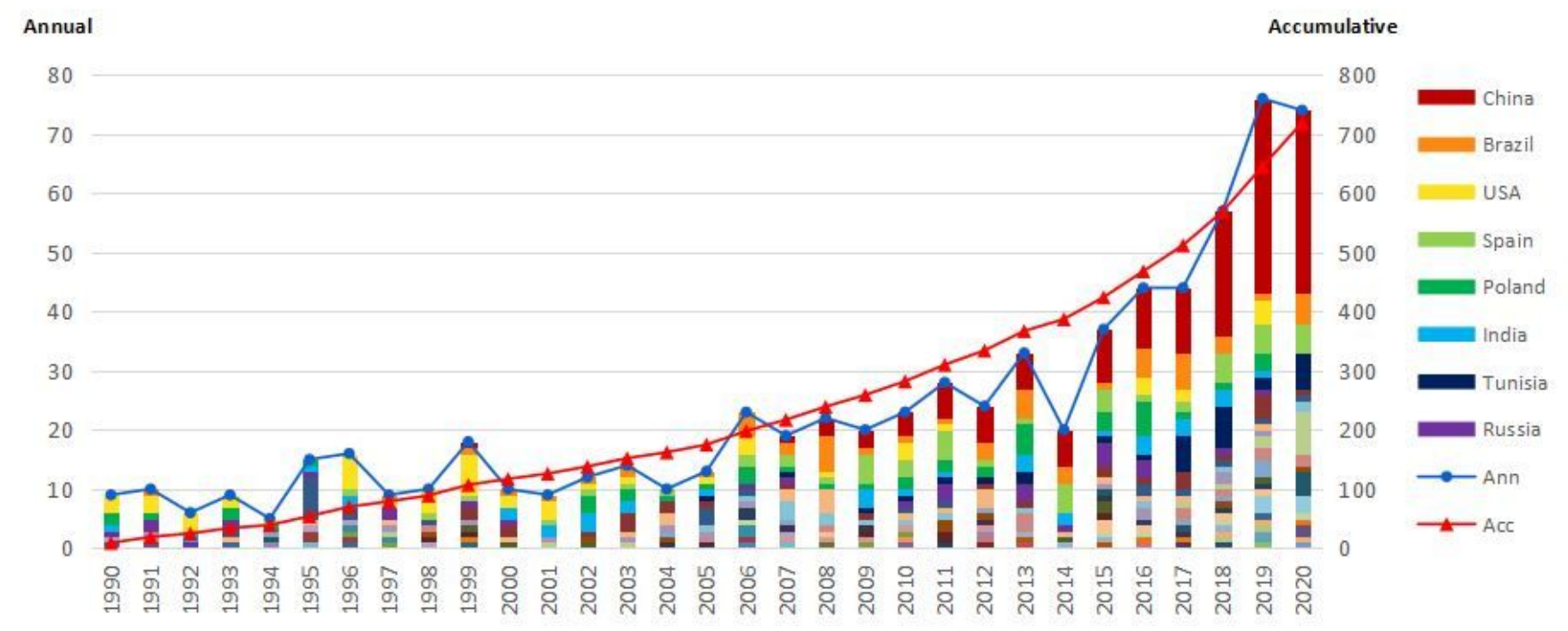

Figure 2

Annual and cumulative articles in PG resource utilization

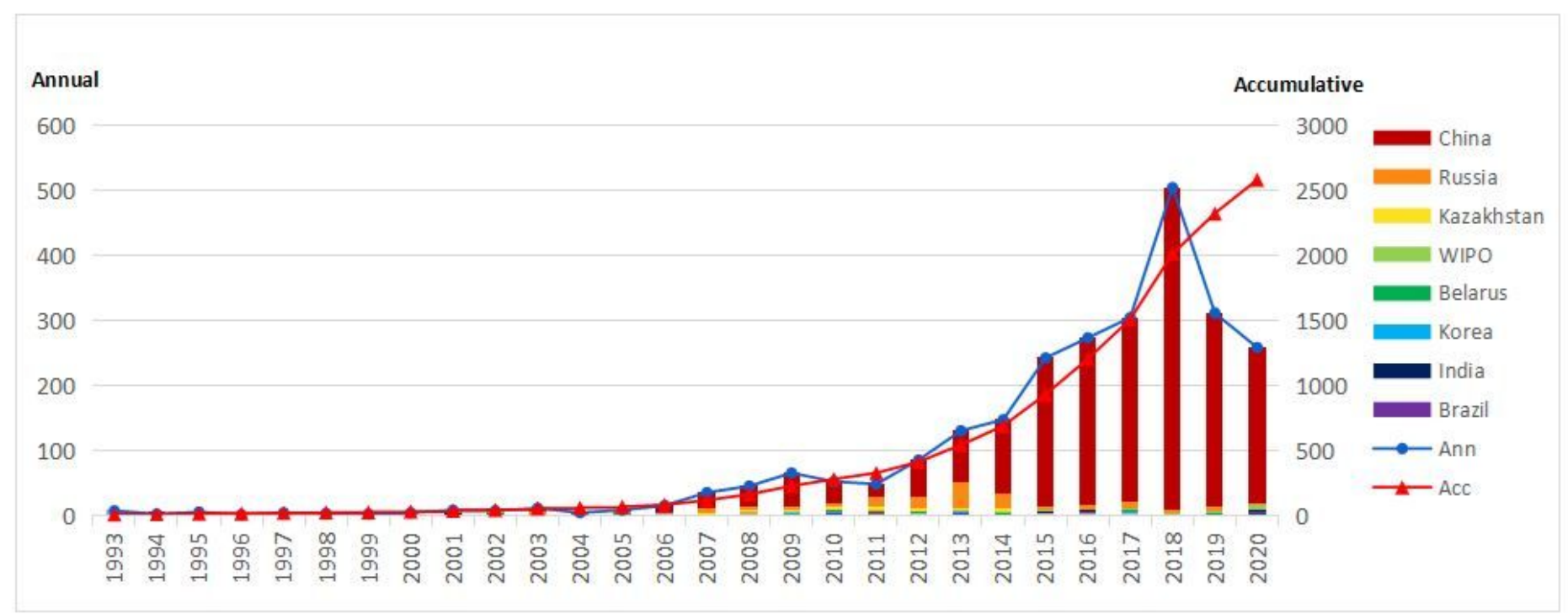

Figure 3

Annual and cumulative patents in PG resource utilization

\section{Supplementary Files}

This is a list of supplementary files associated with this preprint. Click to download.

- Supplementarymaterials.docx 